\title{
Children's Patterns of Composition and their Reflections on their Composing Processes
}

\section{Debra Myhill}

University of Exeter, UK

Word count: 6499 (excluding references, figures and tables)

\author{
Address for Correspondence: \\ School of Education and Lifelong Learning \\ University of Exeter \\ Heavitree Road \\ EXETER EX1 2LU \\ Email: d.a.myhill@ex.ac.uk
}

\begin{abstract}
:
This article reports on an ESRC-funded study into secondary aged writers' compositional processes, both as observed in a naturalistic classroom setting and as gathered through post hoc reflections. The sample comprised 38 children drawn from year 9 and year 11 who were observed, using an annotated timeline, responding to a writing task in the classroom and were subsequently interviewed, using stimulated recall. The initial analysis of the pause and writing patterns observed during the writing task revealed different writing profiles for different writers, and subsequent analysis suggests tentatively that writers of different proficiency may present differing writing profiles. These patterns of composition are then illustrated further through use of the interview data, indicating the writers' awareness of their own composing processes. Finally, the article considers the pedagogic and theoretical implications of these findings, in particular the need for further confirmatory research.
\end{abstract}

Keywords: writing; composing processes; composition; metacognitive awareness 


\section{Children's Patterns of Composition and their Reflections on their Composing Processes}

\section{Introduction:}

Theoretical models of composition have largely developed from Hayes and Flower's (1980) model, which described composition in terms of the sub-processes of generating, translating and reviewing, influenced by the writer's long-term memory and the task environment. They emphasise the recursive, intertwined quality of the writing process, and argue that the stages in the process compete for cognitive attention, regulated by a switching mechanism (the monitor) which moves the writer's attention from stage to stage. The act of writing is conceptualised as 'the act of juggling a number of simultaneous constraints' (Hayes and Flower 1980), constraints which can be external, such as the writing task, the intended audience, or internal, such as knowing what to say and how to say it (Sharples 1999). Since Hayes and Flowers' original 1980 model of the composing process, there have been various adaptations and refinements (for example, Brandt 1992; Berninger and Swanson 1994; Butterfield et al 1996; Hayes 1996). But Alamargot and Chanquoy (2001) argue that common to all models of the writing process are three stages - planning, translating and revising. Broadly speaking, the process of planning includes the retrieval of ideas and information from the long-term memory, the generation of new ideas through synthesis and imagination, and the formation of a pre-verbal message. Translation is the process of moving from pre-verbal ideas and messages into words and text on the page, whilst reviewing involves all processes which judge and evaluate ideas or text produced. The three phases do not occur in a linear, chronological fashion but are intertwined and may even co-occur, for example, when a writer is translating one phrase onto the page but is simultaneously reviewing whether the phrasing is correct. This article reports on children's composing patterns and metacognitive understanding as they move from mental ideas and representations to written text production; the article describes the outcomes of a study of composing processes in classroom settings and argues that greater instructional attention should be attributed to how children write, the variety of composing patterns they adopt, and metacognitive discussion about composing strategies, rather than always focusing on what is written. In particular, the paper calls for more classroom-based research into composing processes which explore not only individual differences, but also whether different sub-groups of writers (such able writers or boys) adopt particular composing behaviours.

\section{Theoretical framework}

\section{Conceptualising the process of translation:}


Hayes and Flower (1980) described translation as the process of transforming generated ideas into sentences and texts. But the boundary between planning and translation is not a rigid one, as the act of writing and verbal production frequently prompts either the generation of new ideas or a revision of the direction of the task. Kellogg (1990) argues that it is useful to distinguish between planning and translation because it discriminates between the initial generation and organization of ideas and messages and the process of communicating those ideas to others in writing; a difference between what Kellogg (1990:30) calls 'personal symbols', understood only by the self, and 'consensual symbols' understood by others. Alamargot and Chanquoy (2001) identify four stages in the translating process: elaboration [retrieving the idea from the plan]; linearization [first transformation of the idea into a syntactico-semantic structure]; formulation [shaping the pre-verbal message into words]; and execution [planning and graphic execution of the linguistic product]. They also note that more research attention has been attributed to planning, rather than translating, and that 'writing models remain unclear concerning the formulation of sentences from a preverbal message' (Alamargot and Chanquoy 2001:76): indeed, in the original Hayes and Flower's graphic representation of their model, the box labelled Translation has no further detail or sub-processes, unlike other boxes. This may be because of a tendency to regard verbal production as unproblematic, as sentence and text production involves 'the application of fixed rules' (Negro and Chanquoy 2005:106), but such a view disregards the potential cognitive load on working memory during translation, particularly for novice writers who may be simultaneously attending to transcription or to aspects of writing such as spelling or punctuation. It also disregards the complexity of shaping and selecting sentences to create meaning, a process which Kellogg describes both as a struggle and a process of 'active construction' (1990:25). For the purposes of this study, we have conceptualised translation as the movement from thoughts in the head to words on the page.

\section{Composing patterns:}

This process of active construction of meaning during translation appears to result in different writing behaviours. In their original proposition of a model of composition, Hayes and Flower (1980) identified four prototypical composing patterns: Depth first, in which the writer attempts to produce perfect sentences, sentence by sentence, reviewing each sentence as the writing progresses; Postponed review, where the writer concentrates first on capturing thoughts on paper and revises later; Perfect first draft, where the writer plans globally and explicitly and attempts to produce a first draft which requires little subsequent revision; and Breadth first, which is characterised by detailed initial planning and creation of a first draft, before revision. Sharples (1999) notes that 
researchers have often broadly viewed writers as either 'discoverers' who use writing to think and generate ideas, as 'a means by which one discovers what one wishes to say' (Odell 1980:143), or 'planners' who devote time to planning and organizing ideas before writing. There have, however, been relatively few detailed empirical studies of translating behaviours, and none in naturalistic settings. Severinson Eklundh's (1994) study developed the notion of a continuum of linearity during translation, whereby simple writing tasks tended to produce more linear writing behaviours than complex writing tasks. She defined non-linearity as the process of interrupting the flow of text production with re-reading, deleting and adding text whilst composing. However, her study addressed writers composing on computers and focused on the relationship between text complexity and writing behaviour. Levy and Ransdell (1996) argue, from a slightly different perspective, that every writer produces a different pattern of composing during translation. However, the most detailed analysis of the composing patterns of experienced writers was conducted by van Waes and Schellens (2003), who conducted a quantitative analysis of writers and compared their composing behaviours when writing on paper or on screen. They analysed writing behaviour in terms of time distributions and pausing and revision behaviour and, using cluster analysis, discriminated five writing profiles:

Insert Table 1

\section{Pause-writing patterns:}

Common to most studies of the translating element of the writing process, and clearly evident in van Waes and Schellens' study, are the identification of periods of writing and periods of pausing, possibly because these are clearly observable behaviours. The precise nature of the cognitive processes occurring during the pause is less evident. Matsuhashi (1981) argued that pauses during the period of text production were principally concerned with generating content at a global or sentence level, or with shaping phrases and sentences to match the purpose of the writing task - in other words, pauses are concerned with what to say and how to say it. Gould (1981) considered pauses in terms of reading text already produced to review it, and planning for what will follow, but his distinction is critiqued by Kellogg (1994) for ignoring that 'planning' pauses could include revising and editing decisions following the reading of text. Both Gould and Kellogg agree that in their studies pausing occupies approximately two-thirds of the writing time. In other studies, the locus of interest is less on the pause activity and more on the writing activity, particularly the length of verbal production between pauses. Hayes and Chenoweth (2006) describe the period of writing between pauses as 'bursts', arguing that usually 'sentences are 
produced in bursts' where 'the writer produces a sequence of words in rapid order, then pauses, produces another sequence, pauses and so on' (Hayes and Chenoweth 2006:138). A burst of writing may produce a sentence, but most typically is produced in clause units, or even single word units. The more fluent a writer, the longer will be the bursts in their writing: indeed, Chenoweth and Hayes (2001) claim that 'burst length is a central contributor to fluency' and is attributable to an increase in 'the capacity of the translator to handle complex language structures' (Chenoweth and Hayes 2001:94). However, writing fluency is measured as the number of words written per minute and does not consider the accuracy or effectiveness of the written text: indeed, Kellogg (1994:62) notes that fluency is only moderately correlated with quality. Moreover, by conceptualising the writing burst as essentially about linguistic production, influenced by 'the limited capacity of the translation process to convert ideas into language' (Hayes and Chenoweth 2006:145), the impact of metacognitive awareness upon the writing process and the role of evaluative judgments and decision-making made during writing are understated.

\section{Methodology}

The research reported here, funded by the ESRC, sought to draw on the insights from psychological research, but to develop a research design which was both classroom-focused and empirically robust. Almost all the research reviewed above is experimental in nature, designed to acquire a better understanding of the cognitive process involved in composition. Hayes (2001) has argued that 'a major goal of researchers in this field should be to apply what is learned through research to improve the quality of writing by studying writing in practical settings' in order to inform and develop writing pedagogy. This applied understanding was a central goal of this study. The sample was drawn from four secondary (age 11-18) schools in the UK, drawing on a mix of rural/urban catchments and each representing socio-economic diversity. The case study sample for the investigation into composing processes drew from two year 9 (age 14) and year 11 (age 16) classes in each school, and involved two children in each class, who were observed and interviewed up to three times over a period of two terms. The final sample comprised 82 observations of 38 children, 20 from Year 9 and 18 from Year 11. Each child in the sample was classified as high-achieving, average-achieving or lower-achieving in writing, using the class teacher's assessment of writing performance against the National Curriculum level descriptors in year 9 and GCSE grades in Year 11 (often the Original Writing coursework grade). The sample was stratified by gender (and the gender implications of this study are reported elsewhere: Jones and Myhill 2007), but no attempt was made to seek ethnic representativeness as the schools were predominantly white. 
The observations were timed to coincide with normal classroom opportunities for writing, where writing was the focus of the teaching. Those children selected as case studies were fully informed about the research and their role in it and their written consent was required before proceeding with the research. Moreover, consonant with the collaborative principles of the study, the research encounters with the case study pupils sought to engage them in thinking about the research question, not simply to use them as research subjects.

Data was collected through observation and through interview after the observation, using a stimulated recall strategy. A deliberate choice was made not to use a think aloud protocol because the cognitive load incurred by thinking aloud while composing 'adds an obvious additional demand to the already heavy demands imposed by composing itself (Kellogg 1994:51) and because it would have been counter to normal classroom practice in writing. Instead, an annotated timeline was devised, which allowed the researcher to capture chronologically the composing actions of the writer, such as pauses, writing flow, and revisions. Where possible, the timeline noted whether pauses occurred mid-sentence (PM) or at the end of a sentence (PE) and noted any changes made to the text during composition. It also noted when the writer started a new line, permitting subsequent comparison of the timeline data with the text produced. An extract from one of the annotated timelines is provided in Figure 1. The naturalistic classroom setting did impose limitations on the data collection as it was not always possible to see whether a pause was mid-sentence or end of sentence, and it was not always possible to capture the nature of revisions made. Equally, although the intention was to capture the data in a naturalistic setting, it must be acknowledged that it is not normal classroom practice to write whilst an observer records the process.

- insert Figure 1 here -

Immediately following the observation, an interview was conducted using stimulated recall: the writer was interviewed with the piece of writing they had composed, and was invited to reflect on both decisions made during writing and recollections of how they composed, prompted by the information on the annotated timeline.

The interviews were analysed using NViVO, using an iterative process, involving the Project Director and Research Fellow jointly coding some interviews as a starting point, then coding separately, then returning to joint checking of the coding, and adjustment of the codes. The software package facilitated considerable checking and cross-checking of the consistency of the coding, both during the coding process and when coding was 
complete. When all the interviews had been coded, every code was re-checked by the Project Director and Research Fellow working together, and this stage included a final refining of the definition for each code.

The analysis of the annotated timeline data was undertaken using EXCEL. The data recorded on the timeline permitted categorization of the writing period in terms of one of two activities, either writing or pausing, with additional information about what writing actions or behaviours occurred in these pauses or writing bursts. For each episode observed, the data was entered into EXCEL with the time spent writing recorded as a positive value and time spent pausing as a negative value: this enabled the production of bar graphs which visually portrayed the composing process in terms of pauses and bursts over the writing period. An initial visual qualitative analysis of these bar charts suggested the key differences in composing processes related to the number of transitions between writing and pausing made by the writer, and to the relative amounts of time spent on writing and pausing. In order to make these visual comparisons more robust, it was decided to take a ten minute period of writing from the start of the writing episode as the unit of analysis. This decision was taken because the time allowed by the teacher for each writing episode varied in practice from 15 minutes to twenty five minutes, and also because each child observed reached different points in the writing task within the time allocated, and some had completed the task more quickly than others. Thus the first ten minutes could reliably be deemed a comparable point in the writing process, whereas the 'middle' and 'end' were not comparable periods. Each writing episode was then analysed in terms of the relative amounts of time spent writing or pausing, and the number of transitions between writing and pausing. The first analysis divided the data into three groups:

- Those who spent more time writing than pausing

- Those who spent more time pausing than writing

- Those for whom the pause-write distribution was more or less balanced

As this first analysis only took into account the overall times spent pausing and writing, the second analysis considered how many transitions between pausing and writing occurred, providing some insight into the relative length of the writing and pausing periods. The mean, median and modal number of transitions ranged between 28 and 31 , so in order to discriminate between writers who made transitions frequently and those who did so 
with less frequency, the sample was divided into those who made more than 24 transitions and those who did not.

\section{Findings: composing patterns}

The process of analysis described identified five groups, who exhibited differing composing patterns:

Brief pausers: those who spent more time writing than pausing, with more than 24 transitions between writing and pausing. This writing profile is typified by having longer periods of writing than pausing, but with writing frequently interrupted by a brief pause. A typical bar graph for the brief pauser is presented below: the short bars below the $\mathrm{x}$ axis and longer bars above the $\mathrm{x}$ axis illustrate the pattern of brief pausing and more extended bursts of writing.

Insert Figure 2 here

Flow writers: those who spent more time writing than pausing, with fewer than 24 transitions between writing and pausing. This writing profile is typified by longer periods of writing and few pause interruptions. These writers tended to finish first, sometimes within the ten minute period. The bar graph below, with its longer bars above the $x$ axis, illustrates the profile of a typical flow writer.

Insert Figure 3 here

Sustained pausers: those who spent more time pausing than writing, with fewer than 24 transitions between writing and pausing. The length of time spent pausing also means there are fewer transitions as the time is occupied by pausing behaviour. This writing profile is typified by lengthy pauses and few brief episodes of writing, as illustrated on the bar graph below.

Insert Figure 4 here 
Rapid switchers: those whose time spent pausing and writing was more or less balanced, with more than 24 transitions between writing and pausing. This writing profile is typified by frequent short bursts of both pause and writing activity and the bar graph is symmetrical about the $x$ axis with short bars.

Insert Figure 5 here

Stop starters: those whose time spent pausing and writing was more or less balanced, with fewer than 24 transitions between writing and pausing. This writing profile is typified by longer bursts of both pausing and writing. The bar graph for stop starters, like that for rapid switchers, shows symmetry along the $x$ axis but is characterised by longer bars.

Insert Figure 6 here

The distribution of writing profiles across the sample was not even, as the table below indicates, with the patterns of rapid switching or brief pausing being the dominant ones presented.

Insert Table 2 here

There was tentative evidence that writers of differing ability may have tendencies towards differing profiles. Although the rapid switcher was the dominant profile for all writers, regardless of attainment, high and average achieving writers populated this group more strongly than lower-achieving writers. $91 \%$ of the high-achieving writers were rapid switchers, stop starters or brief pausers - profiles which either have a more or less even distribution of writing or more time spent writing than pausing, and frequent pause-writing transitions. Conversely, lower-achieving writers were more likely to be flow writers than any other group: their writing profiles were also more distributed across the five different types than either high-achieving, or average-achieving writers.

Insert Table 3 here 
This tendency for lower-achieving writers to have longer bursts of writing than others is confirmed by the numerical analysis which indicates how many transitions from pausing to writing occurred during the ten minute period. This indicated a decreasing number of transitions with declining writing attainment, matching the tentative pattern that high-achieving writers switch frequently, with lots of pause-write transitions, whilst lowerachieving writers have fewer pause-write transitions.

\section{Insert Table 4 here}

However, when the data is analysed according to the time distribution of pausing and writing, rather than the number of transitions between pausing and writing, a slightly different picture emerges. Although all writers observed spent more time writing than pausing, it was the high-achieving writers who spent the most time writing relative to their pausing. Whilst this is consistent with the pattern of the high-achieving writers, of whom $91 \%$ present profiles where writing is more or less matched by pause time (rapid switchers and stop starters) or where writing exceeds pause time (brief pausers), the data for the low achieving writers is more ambiguous. It is not consistent with the pattern of the flow writers, who spend substantially more time writing than pausing. This may be because the lower-achieving writers have the most evenly distributed pattern across the five writing profiles, so although the flow writers are more likely to be lower-achieving writers, lower-achieving writers are not predominantly flow writers.

\section{Insert Table 5 here}

The composing patterns revealed through analysis of the observation data offer some potentially significant insights into differential composing patterns, with correspondingly important implications for pedagogy. However, to be confident that these patterns are generalisable to a wider population, rather than a characteristic of this sample, and to explore with more robustness the contrasting composing patterns by attainment, further research needs to be conducted which examines these composing patterns with a larger, stratified sample.

\section{Findings: metacognitive awareness of composing patterns}


There was, however, a strong correlation between the researcher-observed patterns of composition and children's reflections on their writing processes, and their interviews provide valuable insight into their awareness of their own composing processes. The brief pausers, the group whose composing pattern is one of frequent brief pauses and more extended bursts of writing, appear to be thinking during writing, as well as thinking during pauses. One brief pauser commented that, rather than just 'writing, concentrating on that and then stopping and thinking and then writing', she would be 'thinking about two sentences ahead as I write it which I find means you can write more.. save time'. It appears that brief pausers may be advance planning rather more than others, not only by thinking ahead during writing, but by using pause time not to generate the next idea but to pre-plan later text, as the following writer observes:

- What I do is I write, and basically carry on writing, but when I pause, I'm not thinking about what I'm going to write next, I'm thinking about what's going to happen in two or three paragraphs' time.

In contrast, both the stop-starters and the rapid switchers seemed to use the pause time in part as a way of managing the cognitive demand of translating generated ideas from thought to written text: I usually do think of a sentence at a time or a paragraph at a time, but I usually stop for pauses, because if I think of it all at once, I forget most of it. If I write down a bit at a time and think a bit at a time then I think I get more done. This group appear to be pausing to generate the next sentence, or part of a sentence:

- I was just thinking about what I was going to write next.

- I just think of a first sentence and then gradually build up the sentences as you go on,

- Although in saying that, I realise that what I do is, I just like think of a few words at a time and write them down, I don't usually think of, like, whole...it's hard for me to think of, like, big sentences.

The flow writers, who were more likely to be lower-achieving writers, were more concerned to capture their ideas on paper, and claimed to delay thinking about the effectiveness of the writing till later. One flow writer reflected that she would generally 'write as I go along then I'll go back and make corrections later', whilst another expressed a dislike for checking during writing, preferring to check post-completion: 'Well, I don't really like checking half-way through; I like writing it all, then checking it all through'. These responses perhaps suggest that lower-achieving writers do less thinking, planning and reflecting during the translation stage than high- 
achieving writers. However, the researcher observations indicated that post-completion revision and alteration was a rare occurrence, and where it did happen it was confined to surface feature corrections. Indeed, the flow writers refer to 'correction' and 'checking', indicating that their thinking about the effect of their writing may be more concerned with technical accuracy than with compositional effectiveness.

The sustained pausers, on the other hand, do not write and then correct: their writing is interspersed with long pauses. From the post-hoc reflections, it was evident that these pauses were filled with two rather different kinds of activity. For some, the pauses were periods where they were experiencing a block, where they did not know what to write: 'sometimes, I just get a blank and can't really think about what I'm writing'. For some sustained pausers, a strategy for overcoming a block was to use this pause time to re-read their writing so far in the hope that it would generate more ideas: 'I just read it through again and sit there until I know.' For others, however, the pause times were prompted by dissatisfaction with something they had written, a sense that 'this isn't really working'. Many of these pauses occurred mid-sentence, and were triggered by dissatisfaction with the opening segment of the sentence: 'I started a sentence and didn't think that would work'. The pause time was used to attempt to resolve these perceived problems.

\section{Findings: Starting patterns}

The annotated timelines also permitted analysis of the starting behaviour when tackling a composition task. In piloting the timeline, it became evident that there were some methodological difficulties to resolve in capturing this data as it is relatively easy to observe when writing begins with writing, but when it begins with a pause, it is harder to determine the precise start time. It was not possible to begin timing from the point the teacher had given the instruction to begin, as we had originally intended, as there were other activities which occurred at this point which were effectively 'preparing for writing' tasks, rather than compositional processes, such as finding a pen; finding the right page in the exercise book, or clarifying the task with a teacher or peer. We therefore decided to begin timing from the moment the writer picked up the pen and appeared to be engaged with the task of writing. A number of writers began by writing the date and title, and then paused: for the purpose of the analysis of starting behaviour, we included this as pause time. Nonetheless, it is important to acknowledge the difficulty of ascertaining precisely when composition begins, as writers may well be thinking about the task while finding a pen, and clarifying the task with peers or a teacher may likewise be an important phase in composition. 
The data revealed that the majority of composing periods began with a pause, but that this tendency was markedly more apparent with average and high-achieving writers, than with lower-achieving writers. Indeed, it is the average-achieving writers who were most likely to pause.

\section{Insert Table 6 here}

The interviews indicated that those who started by writing were considerably more conscious of why they chose this as a starting strategy - in line with Odell's claim that some writers are discovery writers (Odell 1980:143), these children were writing in order to find out what to say. For these writers, the act of writing supported the generation of ideas and created an impetus for what to write next. The comments below were typical of this group:

- I just really get on with it and things start coming into your head.

- Well, I didn't know what I was going to write about and then I just decided that, start and see if I got any ideas when I started writing.

口 It just flows really; I just start writing ... as I write it just comes to me and new words, new sentences, just different things, different ideas...

- As I'm writing it just kind of comes from there; it just flows and I just get more and more ideas.

By contrast, the interviews with those who began the composing period with a pause were more varied, indicating that writers were less clear in articulating how they used this pause time One definite group were those who began the composing period by task representation: by thinking through the writing task and its demands. One writer reflected that she used this pause time to think 'about what we have to do and how we've got to do it', whilst another writer thought 'about how I'm going to start the story and how I'm going to continue it'.

One feature of all the observations was the very limited use of written planning prior to starting the first draft. Very few of the writer-starters began by writing a plan or any form of pre-writing organiser, and some were aware of varying strategies regarding planning: 'some people presumably find it easier to plan something before they 
write it, but I find it easier just to sit down and write it'. One of the few writers who did complete a written plan believed that this had made the subsequent composing period much easier:

- This one I found quite easy because l'd made quite a easy plan, like what I was doing for each of the paragraphs so all I really needed to do was think up the sentences but I already knew what they were going to be about...

There was evidence, however, that some of the students who began with a pause used this time for mental planning, perhaps as an alternative to formal written planning:

ㅁ I think about it in my head first. I think before I write.

- I'll probably just think about it in my head, how I'm going to set it out and then do it after l've thought about it

There was little evidence that there was any relationship between writing competence and the planning strategies used (or not used), though the reflections of some of the high-achieving writers did suggest that it was easier to begin writing quickly when the task demand was familiar. One boy claimed that 'once I get going in a piece, they're all roughly the same. You just keep going, on a roll, I think'. It may be that these high-achieving writers have successfully internalized writing structures, what Hayes and Flower (1980) described as stored writing plans in their model, and this supports the process of composition.

\section{Discussion:}

The study highlights that for these children (12-16 years old), with varying degrees of writing maturity, there are a range of different composing patterns evident. There seems to be a high degree of confirmatory correlation between the patterns observed in this naturalistic study and those discerned in an experimental setting by van Waes and Schellens (2003). In particular, their non-stop writers parallel our flow writers; fragmentary stage 1 writers parallel our rapid switchers; and Stage 2 writers may parallel sustained pausers in this study.

The study also suggests, with some tentativeness, that there may be relationships between composing patterns adopted and success in writing, though to suggest that there is a direct correlation between composing pattern 
and the eventual quality of the writing produced from the sample size here would be unwise. We are unable to say with certainty whether, for example, it is the writing ability which is significant in shaping the composing pattern adopted or vice versa. However, the notion that there might be a relationship between the composing processes and the writing produced has been posited by van den Bergh and Rijlaarsdam (2001) who have argued that we should look at the impact of different processes on writing quality. In their study, they found better writing was produced by those who spent more time thinking in the initial period of composition, rather than beginning writing immediately. There is evidence from the writers' reflections in our study that highachieving writers may have internalized writing structures and so may need to pause more briefly than less confident writers who need to pause to think consciously about what to write. There was also evidence that the high-achieving writers were engaged in more advance planning, editing and revision during writing than less confident writers. The brief pausers, who were predominantly high-achieving writers, claimed to plan whilst writing as well as during pauses, possibly indicating a greater facility to manage cognitive resources during writing. The patterns of writing and pausing presented by rapid switchers and stop starters appears to be a strategy to manage the cognitive demand of moving from ideas to written words and as these groups are populated more by high-achieving and average-achieving writers, it is possible that their greater awareness or motivation to produce an effective piece of writing increases the cognitive demand of the translation process. Certainly, the stop-starters and rapid switchers pause to generate the next sentence or next idea, but were less likely than the brief pausers to have an advance plan or global view of the text they were composing. This contrasts with the tendency of the flow writers, who as lower-achieving writers, seemed more concerned to finish the writing task, than to think about what they were writing and its effect. If task completion is the goal, rather than attention to the quality of the piece, the cognitive task demand during writing is reduced.

Kellogg (1994) notes that in his research of time distributions during writing, approximately two-thirds of a writing period were occupied by pause time. This study presents a rather different pattern, with high-achieving writers spending considerably more time writing than pausing, and the lower-achieving writers having a more balanced distribution of writing and pausing (though the latter as an average is distorted by the flow writers who spend more time writing than pausing). It is possible that the patterns in our study are more strongly reflective of school writing patterns, rather than the composing patterns of expert writers writing for a purpose. However, the interviews with children about their composing patterns and about activities they are engaged upon during pauses suggests that the time spent pausing may be less significant than the nature of thinking during the 
pause. Alternatively, different conceptualizations of the writing task and differing internalized structures for writing may be influencing the pause-write distributions and transitions. Further research which takes these tentative findings and explores them in the context of larger samples and a variety of methodological approaches would be valuable in establishing the replicability of the findings of this study. Such research might usefully address not only individual differences, but also whether different sub-groups of writers (such able writers or boys) adopt particular composing behaviours.

These different composing patterns do suggest implications for writing pedagogy. The close alignment between the researcher-observed patterns of composing and children's recollections of how they composed suggests that these writers have a reasonably well-developed metacognitive awareness of their own composing processes. Although there is a well-documented and influential body of pedagogical material which advocates a process approach to writing (Graves, 1983; Emig, 1988), Czerniewska 1992:84 claims this has tended to become institutionalized, or even ritualised into a programmatic approach to writing, embodied by stages of planning, drafting, revising and editing. In the National Curriculum for English (DfEE 1999) and the National Literacy Strategy/Key Stage 3 Framework for English, the ability to 'plan, draft, write and edit' is circumscribed as a body of knowledge to be taught in both primary and secondary schools. It may be unwise for policy to dictate writing behaviour quite so categorically, given the variations in composing patterns found by others in experimental settings, and confirmed here in classroom settings. Given that the study found that high-achieving writers spent more time writing than planning, counter to earlier research with expert writers, we may also need to rethink classroom strategies related to planning. The axiomatic advocacy of planning before writing may need to be replaced by a more differentiated approach to planning which not only takes account of differing composing behaviours but also by a recognition that planning skills may not yet be well developed even in able writers.

Graves' (1983) notion of the conference is potentially an opportunity to engage in metacognitive discussion about writing, but his descriptions of conferencing appear to be more focused on the writing produced, rather than on the process of writing. Indeed, this focus on the writing produced at various stages is equally characteristic of the post-process movement in composition studies, although the emphasis shifts to the ways in which meanings are created and interpreted in written texts: McComiskey (2000), for example, frames the process of writing as rhetorical enquiry, which encourages writers to think about their writing in terms of the cycle of production, distribution and consumption. Whilst consideration of what is written and how meanings are made 
is important and valuable, building explicit opportunities for writers to discuss how they write, their composing patterns and their thinking strategies, might be beneficial in exploring the most productive and efficient ways for an individual to approach a writing task. The importance of metacognitive awareness in writing is a recurrent theme in the literature (Kellogg, 1994; Wallace and Hayes 1991; Alamargot and Chanquoy, 2001). Despite the suggestion that 'a great part of the skill in writing is the ability to monitor and direct one's own composing process' (Hayes and Flower 1980 :39), as yet instructional attention to developing metacognition in writing in classroom settings has been limited. Such metacognitive discussion about composing processes might lead writers to reconsider their approaches, and teachers might encourage writers in some circumstances to adapt or alter their writing processes. Greene (1995) explored how writers from different cultural and educational backgrounds appeared to adopt different composing strategies, and recommended that teachers acknowledge this more directly; this study has indicated that differences in composing patterns may also vary by individual or by ability, and monolithic pedagogic approaches which assume homogenous composing patterns may not be sufficiently attuned to individual needs and differences.

Some of the composing patterns illuminated by this study may be worth specific pedagogic attention. Flow writers, whose goal appeared to be completion, may be deploying a strategy which enables composition, but not the shaping of that composition for purpose and effect, and writers who adopt this pattern may need greater strategic support for post hoc drafting and revision, or for task representation at the outset. Likewise, the dominant patterns of stop-starting and rapid switching, where writers paused to generate the next idea, may indeed be a productive generational process: writing to find out what to say and re-reading text at a local level to generate the next idea were repeated themes in the interviews with these writers. But these writers may need further support for advance planning or sophisticated revision. Likewise, teachers could consider supporting writers in developing metacognitive awareness of how to use the start time of writing productively, whether that be through mental planning or written planning. The ability of some writers to represent the writing task to themselves before writing resonates with the research of van den Bergh and Rijlaarsdam (2001) who found a correlation found between text quality and writers who had high task representation scores for the start of the writing period. Even in process approaches to the teaching of writing, pedagogic discussions tend to focus upon the writing produced, be they drafts or finished pieces, rather than on developing self-awareness of composing processes. Kellogg (1994:213) noted that effective teaching of writing 'must teach the student how to think as 
well as write': we may only be able to produce better writers once we have enabled children to become better thinkers about writing. 


\section{References:}

Alamargot, D. and Chanquoy, L. (2001) Through the Models of Writing (Dordrecht, Kluwer Academic Publisher). Bereiter, C. \& Scardamalia, M. (1987) The Psychology of Written Composition (Hillsdale NJ, Lawrence Erlbaum Associates).

Bereiter, C. and Scardamalia, M. (1982) From conversation to composition: the role of instruction in a developmental process, in: R. Glaser, R (ed)_Advances in Instructional Psychology Vol 2, (Hillsdale NJ, Lawrence Erlbaum Associates).

Berninger, V.W. and Swanson, H.L. (1994) Modification of the Hayes and Flower model to explain beginning and developing writing, in: E Butterfield (ed) Advances in Cognition and Educational Practice Vol 2: Children's Writing: towards a process theory of development of skilled writing (Greenwich CT, JAI Press).

Brandt, D. (1992) The cognitive as the social: an ethnomethodological approach to writing process research, Written Communication, 9, 315-355.

Butterfield, E.C. Hacker, D.J. and Albertson, L.R. (1996) Environmental, cognitive and metacognitive influences on text revision, Educational Psychology Review, 8 (3) 239-297

Chanquoy, L. (2001) How to make it easier for children to revise their writing: A study of text revision from $3^{\text {rd }}$ to $5^{\text {th }}$ grades, British Journal of Educational Psychology, 71 (1) 15-41

Chenoweth, N.A. and Hayes, J. (2001) Fluency in Writing: Generating text in L1 and L2 Written Communication, 18, 80-98.

Creber, P. (1990) Thinking Through English (Milton Keynes, Open University Press).

Czerniewska, P. (1992) Learning about Writing (Oxford, Blackwell)

DfE (1998) (re-issued by DfEE, 2001) National Literacy Strategy Framework for Teaching (London, DfE)

DfEE/QCA (1999) The National Curriculum for England: English (London, HMSO)

Emig, J. (1988) Writing, Composition and Rhetoric, in: N. Mercer (ed) Language and Literacy from an Educational Perspective: Vol 2 (Milton Keynes, Open University Press).

Gould, J. D. (1981). Composing letters with computer-based text editors. Human Factors, 23, 593-606.

Graves, D. (1983) Writing: Teachers and Children at Work (New Hampshire, Heinemann).

Greene, Stuart. "Making Sense of My Own Ideas: The Problems of Authorship in a Beginning Writing Classroom." Written Communication 12 (April 1995): 186-218.

Hayes, J. and Flower, L. (1980) Identifying the Organisation of Writing Process, in: L. Gregg and E. Steinberg (eds) Cognitive Processes in Writing (Hillsdale NJ, Lawrence Erlbaum Associates).

Hayes, J.R. (1996) A new framework for understanding cognition and affect in writing, in: C.M.Levy and S. Ransdell (eds) The Science of Writing: Theories, methods, individual differences and applications (Mahwah NJ, Lawrence Erlbaum Associates).

Hayes, J.R. and Chenoweth, A. N. (2006) Is Working Memory involved in the transcribing and editing of texts? Written Communication, 23 (2) 135-149.

Jones, S and Myhill D.A (2007) Discourses of Difference: Examining Gender Difference in Linguistic Characteristics of Writing Canadian Journal of Education (forthcoming)

Kellogg, Ronald. T. (1994) The Psychology of Writing (Oxford, Oxford University Press).

Levy, C.M and Ransdell, S. (Eds) (1996). The Science of Writing. Mahwah, NJ: Lawrence Erlbaum Associates 
Matsuhashi, A. (1981). Pausing and planning: the tempo of written discourse production. Research in the Teaching of English, 15 (2), 113-134.

McComiskey, Bruce. Teaching Composition as a Social Process. Logan: Utah State Univ. Press, 2000.

Negro, I. and Chanquoy, L. (2005) The Effect of Psycholinguistic research on the teaching of writing $L 1$ Studies in Language and Literature 5 (2) 105-111

Odell, Lee. (1980) Teaching Writing by Teaching the Process of Discover: An Interdisciplinary Enterprise, in L. Gregg and E.Steinberg (eds) Cognitive Processes in Writing. (Hillsdale NJ, Lawrence Erlbaum Associates ).

Severinson Eklundh, K. (1994). Linear and nonlinear strategies in computer-based writing. Computers and Composition 11, 203-216.

Sharples, M. (1999) How We Write: Writing as Creative Design (London, Routledge).

Smagorinsky, P. (1987) Graves Revisited: A look at the methods and conclusions of the New Hampshire study, Written Communication, 14 (4) 331-342

Smith, J. and Elley, W. (1998) How Children Learn to Write (London, Longman).

Van den Bergh, H. and Rijlaarsdam, G. (2001) Changes in Cognitive Activities during the Writing Process and relationships with Text Quality, Educational Psychology, 21 (4) 373-382.

Van Waes, L. and Schellens, P.J. (2003) Writing Profiles: the effect of the writing mode on pausing and revision patterns of experienced writers Journal of Pragmatics 35, 829-853.

Wallace, D. and Hayes, J (1991) Redefining revision for freshmen Research in the Teaching of English 25 (1) 54 66.

Wyatt-Smith, C. and Murphy, J. (2001) What English counts as Writing Assessment? English in Education 35 (1) $12-31$. 


\begin{tabular}{|l|l|}
\hline Initial Planners: & devote time to initial planning; long pauses at start; more pausing overall than average. \\
\hline Average writers: & combine characteristics of the other writing profiles and have no clear profile. \\
stage 1 writers: & $\begin{array}{l}\text { start writing their text almost immediately, and devote little time to initial planning; a lot } \\
\text { of revision takes place during first phase of writing. Their writing process is highly } \\
\text { fragmented and characterized by lots of short pauses }\end{array}$ \\
\hline Stage 2 writers: & $\begin{array}{l}\text { postpone revisions to the stage in which they are rereading/reviewing their first draft, } \\
\text { i.e. the second writing phase. They spend quite some time on initial planning, but once } \\
\text { they start writing, they pause relatively infrequently. However, any pauses they do } \\
\text { make are relatively long. }\end{array}$ \\
\hline Non-stop writers: & $\begin{array}{l}\text { revise very little and hardly ever pause while writing. They tend to spend little time on } \\
\text { initial planning and complete their writing task more quickly than others. }\end{array}$ \\
\hline
\end{tabular}

Table 1: summarised from van Waes and Schellens 2003:845)

\begin{tabular}{|c|c|c|}
\hline Rapid switchers & 32 & $39 \%$ \\
\hline Stop starters & 8 & $10 \%$ \\
\hline Brief pausers & 25 & $30 \%$ \\
\hline Long pausers & 8 & $10 \%$ \\
\hline Flow writers & 9 & $11 \%$ \\
\hline Total & 82 & $100 \%$ \\
\hline
\end{tabular}

Table 2: Distribution Pattern of Composing Processes

\begin{tabular}{|l|c|c|l|l|l|l|}
\hline & Rapid switchers & Stop starters & Brief pausers & Long pausers & Flow writers & Total \\
\hline & $32(39 \%)$ & $8(10 \%)$ & $25(30 \%)$ & $8(10 \%)$ & $9(11 \%)$ & 82 \\
\hline Attainment & & & & & & \\
\hline High-achieving & $16(43 \%)$ & $3(8 \%)$ & $15(40 \%)$ & $1(3 \%)$ & $2(6 \%)$ & 37 \\
\hline Average-achieving & $10(47 \%)$ & $1(5 \%)$ & $5(24 \%)$ & $4(19 \%)$ & $1(5 \%)$ & 21 \\
\hline Lower-achieving & $6(25 \%)$ & $4(17 \%)$ & $5(21 \%)$ & $3(12.5 \%)$ & $6(25 \%)$ & 24 \\
\hline
\end{tabular}

Table 3: Composing Processes presented according to writing ability 


\begin{tabular}{|l|l|l|l|l|}
\hline & All & $\begin{array}{l}\text { High- } \\
\text { Achieving }\end{array}$ & $\begin{array}{l}\text { Average- } \\
\text { achieving }\end{array}$ & $\begin{array}{l}\text { Lower- } \\
\text { achieving }\end{array}$ \\
\hline $\begin{array}{l}\text { Number of transitions from pausing to } \\
\text { writing in ten minute period }\end{array}$ & 28 & 31 & 27 & 23 \\
\hline
\end{tabular}

Table 4: Transition Patterns presented according to writing ability

\begin{tabular}{|l|l|l|l|l|}
\hline Time Distribution & All & $\begin{array}{l}\text { High- } \\
\text { achieving }\end{array}$ & $\begin{array}{l}\text { Average- } \\
\text { achieving }\end{array}$ & $\begin{array}{l}\text { Lower- } \\
\text { achieving }\end{array}$ \\
\hline Pausing & 43 & 39 & 49 & 45 \\
\hline Writing & 57 & 61 & 51 & 55 \\
\hline
\end{tabular}

Table 5: Pause-Writing Patterns presented according to writing ability

\begin{tabular}{|l|c|c|c|c|}
\hline $\begin{array}{l}\text { Starting behaviour } \\
\text { expressed as \% }\end{array}$ & All & $\begin{array}{l}\text { High- } \\
\text { achieving }\end{array}$ & $\begin{array}{l}\text { Average- } \\
\text { achieving }\end{array}$ & $\begin{array}{l}\text { Lower- } \\
\text { achieving }\end{array}$ \\
\hline Pausing & 60 & 62 & 71 & 46 \\
\hline Writing & 40 & 38 & 29 & 54 \\
\hline
\end{tabular}

Table 6: Starting Behaviour presented according to writing ability 


\begin{tabular}{|c|c|c|}
\hline TIME & BEHAVIOUR & $\begin{array}{c}\text { LINE } \\
\text { NO. }\end{array}$ \\
\hline 0.00 & $\mathrm{~W} \rightarrow 0.19 \quad \mathrm{P}$ to hand in $\mathrm{HW} \rightarrow 0.22 \quad \mathrm{~W} \rightarrow$ & 1 \\
\hline 0.27 & $\mathrm{~W} \rightarrow 0.35 \quad \mathrm{PM}$ (fun) $\rightarrow 0.42 \quad \mathrm{~W} \rightarrow$ & 2 \\
\hline 0.51 & $\begin{array}{l}\mathrm{W} \rightarrow 0.55 \mathrm{PM} \text { (happen) } \rightarrow 0.57 \mathrm{~W} \rightarrow 1.12 \quad \mathrm{PM} \text { (children) } \rightarrow 1.23 \\
\mathrm{~W} \rightarrow 1.28 \mathrm{PM} \rightarrow 1.34 \quad \mathrm{~W} \rightarrow 1.36 \mathrm{P} \rightarrow 1.43 \mathrm{~W} \rightarrow\end{array}$ & 3 \\
\hline 1.43 & $\begin{array}{l}\mathrm{W} \rightarrow 1.48 \mathrm{PM} \text { re-reading; } \rightarrow 2.05 \mathrm{~W} \text { crossed out 'again'; crossed out quite big section } \\
\text { and wrote 'what would' above } \rightarrow 2.23 \mathrm{~W} \rightarrow 2.36 \quad \mathrm{Pm} \rightarrow 2.38 \mathrm{~W} \rightarrow 2.43 \quad \mathrm{P} \rightarrow 2.48 \\
\mathrm{~W} \rightarrow\end{array}$ & 4 \\
\hline 2.48 & $\mathrm{~W} \rightarrow 2.57$ PM crossed out 'exercise' $\rightarrow 3.13 \quad \mathrm{~W} \rightarrow 3.20 \quad$ PM (entire $\rightarrow 3.27 \mathrm{~W} \rightarrow$ & 5 \\
\hline 3.30 & $\mathrm{~W} \rightarrow$ & 6 \\
\hline 3.50 & $\begin{array}{lll}\mathrm{W} \rightarrow 3.59 & \mathrm{PM} \rightarrow 4.03 \quad \mathrm{~W} \rightarrow 4.05 & \text { PE re-reading; changed 'what would' on L3 } \rightarrow 4.48 \\
\mathrm{~W} \rightarrow 4.57 & \text { PM crossed out 'occur if' } \rightarrow 5.02 \quad \mathrm{~W} \rightarrow\end{array}$ & 7 \\
\hline 5.05 & $\mathrm{~W} \rightarrow 5.13 \quad \mathrm{PM}$ (governors) $\rightarrow 5.26 \quad \mathrm{~W} \rightarrow 5.35 \quad \mathrm{PM}$ (school) $\rightarrow 5.40 \quad \mathrm{~W} \rightarrow$ & 8 \\
\hline 5.41 & $\mathrm{~W} \rightarrow 5.54 \quad \mathrm{PM}$ (to) $\rightarrow 5.58 \quad \mathrm{~W} \rightarrow 6.07 \quad \mathrm{PM}$ (trips) $\rightarrow 6.13 \quad \mathrm{~W} \rightarrow$ & 9 \\
\hline 6.23 & $\mathrm{~W} \rightarrow 6.28 \quad \mathrm{PM}($ abroad) $\rightarrow 6.35 \quad \mathrm{~W} \rightarrow 6.51 \quad \mathrm{PM}$ (their) $\rightarrow 6.56 \mathrm{~W} \rightarrow$ & 10 \\
\hline 6.56 & $\mathrm{~W} \rightarrow 6.59 \quad \mathrm{PM} \rightarrow 7.07 \mathrm{~W} \rightarrow 7.15 \quad \mathrm{PM}($ as) $\rightarrow 7.20 \mathrm{~W} \rightarrow$ & 11 \\
\hline 7.20 & $\mathrm{~W} \rightarrow 7.27 \mathrm{PM}$ (congratulations) $\rightarrow 7.32 \mathrm{~W} \rightarrow$ & 12 \\
\hline
\end{tabular}

Figure 1 - An example of an annotated timeline

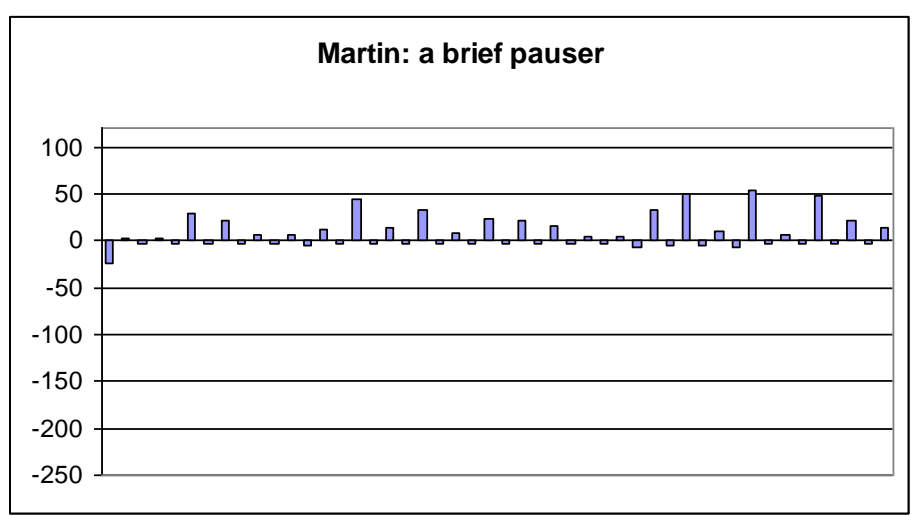

Figure 2: Writing Profile of a Brief Pauser 


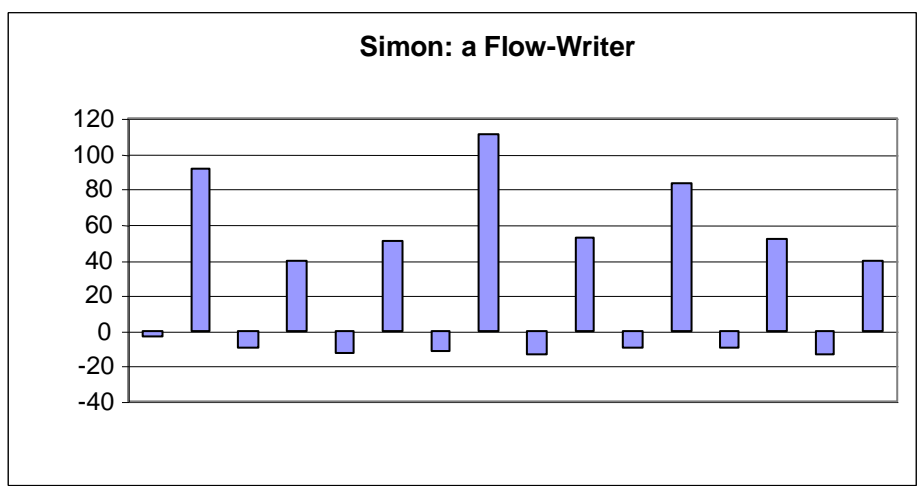

Figure 3: Writing Profile of a Flow Writer

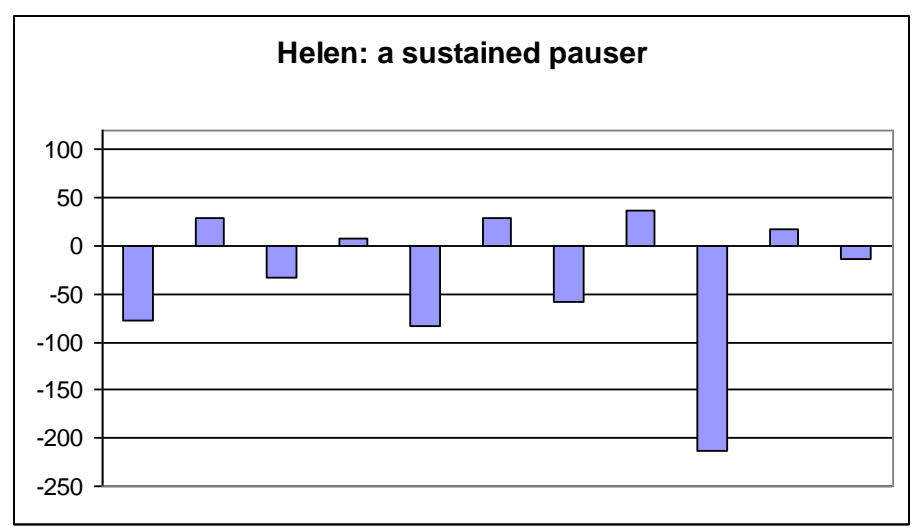

Figure 4: Writing Profile of a Sustained Pauser

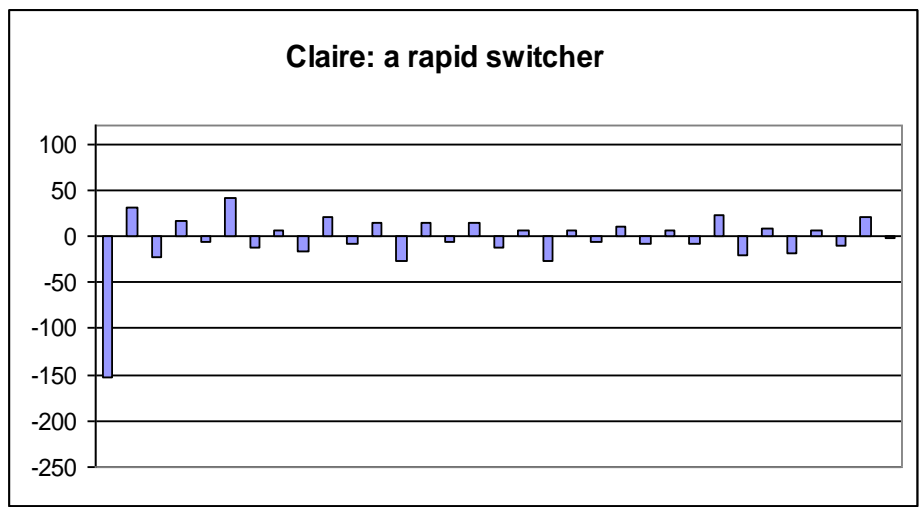

Figure 5: Writing Profile of a Rapid Switcher 


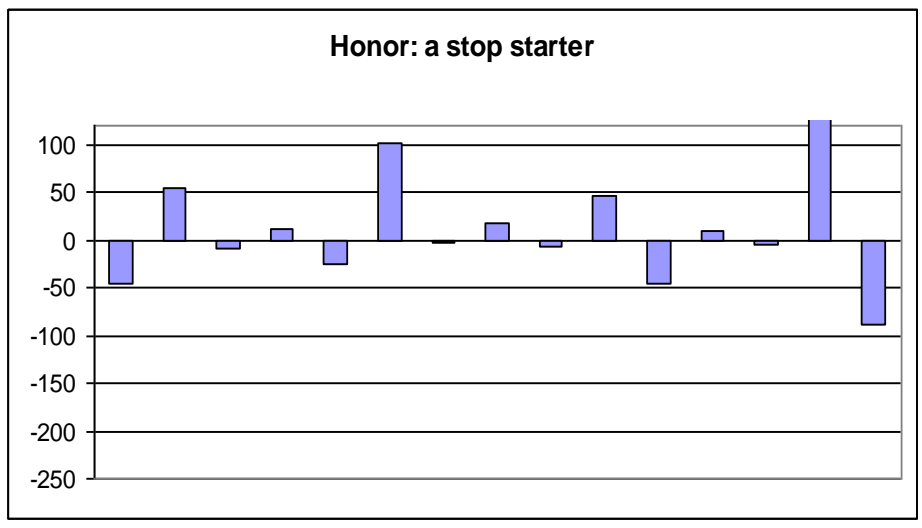

Figure 6: Writing Profile of a Stop Starter 